\title{
Standard for TB care in India (STCI) guidelines- A study on knowledge, attitude and practice among junior doctors of a tertiary care hospital of Kolkata
}

\author{
Debasish Sinha ${ }^{1}$, Mausumi Basu ${ }^{2}$, Abhishek De ${ }^{3, *}$, Kajari Bandyopadhyay ${ }^{4}$, Sitikantha Banerjee ${ }^{5}$ \\ ${ }^{1}$ Assistant Professor, ${ }^{2}$ Associate Professor, ${ }^{3}$ Demonstrator, ${ }^{1-3}$ Dept. of Community Medicine, Institute of Post-Graduate Medical \\ Education and Research, Kolkata, ${ }^{4}$ Specialist Medical Officer, Dept. of Community Medicine, Calcutta National Medical \\ College, Kolkata, ${ }^{5}$ Specialist Medical Officer, Dept. of Community Medicine, Burdwan Medical College, Kolkata, India
}

\section{*Corresponding Author:}

Email: dr.abhishek.de@gmail.com

\begin{abstract}
Introduction: Standards for TB Care in India was produced in 2014 which set out the standard of TB treatment and TB testing \& diagnosis in India that should be provided by the RNTCP in all parts of the country.

Objectives: to assess the knowledge, attitude and practices regarding Standards for TB Care in India (STCI) guidelines among junior doctors in a Tertiary Care Teaching Hospital of Kolkata.

Materials and Methods: An institution-based observational descriptive study, cross-sectional in design, was conducted among 244 junior doctors of a tertiary care Government Teaching Hospital of Kolkata, from May 2016 to June 2016 using a pre designed pre tested structured questionnaire.

Results: Though junior doctors had satisfactory knowledge about symptoms of presumptive TB \& diagnosis; they had unsatisfactory knowledge regarding drug regimen, follow up sputum, diagnosis of MDR TB, XDR- TB and TB HIV.; they had positive attitude regarding seriousness of TB and regular upgradation of TB knowledge and had discordant practices regarding drug regimen, duration of treatment and TB notification.
\end{abstract}

Conclusions: Structured and periodic training and re-training to ensure continuity of correct knowledge is need of the hour.

Keywords: STCI, Junior doctors, Knowledge, Attitude, Practice.

\section{Introduction}

Globally 10.4 million incident cases of TB occurred in 2016; $90 \%$ were adults; $45 \%$ were male; among which 6.3 million new cases were reported, equivalent to $61 \%$ of the estimated incidence cases. ${ }^{1}$ Worldwide in 2016, an estimated $4.1 \%$ of new cases and $19 \%$ of previously treated cases had Multi Drug Resistant (MDR)/Rifampicin Resistant (RR)-TB. ${ }^{1}$ Tuberculosis is the ninth leading cause of death globally; the leading cause from a single infectious agent, even ranking above HIV/AIDS. In 2016; an estimated 1.3 million deaths occurred due to TB among HIV-negative people and additionally 3,74, 000 deaths among HIV-positive people. ${ }^{1}$

India has highest burden of both Tuberculosis and MDR-TB and second highest burden of HIV associated TB; based on WHO Global TB report 2017. ${ }^{1}$ India accounts for about $25 \%$ of the global TB burden. In 2016 an estimated 2.8 million TB cases occurred and 4.5 lakh people died due to TB. ${ }^{2}$ About $2.8 \%$ among new TB cases \& $12 \%$ among previously treated TB cases have MDR-TB. ${ }^{3}$

Standards for TB Care in India was produced in 2014 which set out the standard of TB treatment and TB testing \& diagnosis in India that should be provided by the RNTCP in all parts of the country. ${ }^{4}$

In March 2017, the Government of India (GoI) announced that the new aim in India with regard to TB would be the elimination of TB by 2025- elimination defined by the World Health Organisation (WHO), is that there should be less than 1 case of $\mathrm{TB} /$ million population. $^{5}$
Although some studies in India and abroad have documented inadequate TB knowledge, unfavorable attitude and bad practices among practicing physicians, such studies in junior doctors are very few in our country.

With this context the present study was carried out to assess the knowledge, attitude and practices regarding Standards for TB Care in India (STCI) guidelines among junior doctors in a Tertiary Care Teaching Hospital of Kolkata.

\section{Materials and Methods}

Study type, Study Design, Study Setting, Study Period: An institution-based observational descriptive study, cross-sectional in design, was conducted among junior doctors of a tertiary care Government Teaching Hospital of Kolkata, during 1-month period, from May 2016 to June 2016.

Study Population: Junior Doctors of that Hospital. Inclusion Criteria: Junior Doctors (interns, externs, house-staffs, postgraduate diploma \& degree trainees [PGTs]) of all ages, both gender, who gave informed written consent to participate in the study and were present on the scheduled period of data collection.

Exclusion Criteria: Post-doctoral Trainees (PDTs), Faculty members and who were not willing to participate in the study.

Study Tool: A Pre-designed, structured, pre-tested self administered questionnaire

The questionnaire had five parts: Part I consisted of information on the sociodemographic profile (5 items); Part II had questions regarding knowledge about STCI 
guidelines (20 items with a total score of 20); Part III dealt with attitude of the study population toward STCI guidelines (4 statements with a total score of 4); Part IV was concerned about practices of the participants regarding STCI guidelines (4 practices with a total score of 4); and Part IV had Source(s) of information about STCI.

The questionnaire was designed in consultation with three experts, two from community medicine, and one from chest department; it was pretested on 20 randomly selected junior doctors of the same institution; their views were collected and necessary changes were made. The junior doctors who were participated in the pilot study were not included in the study sample.

Study Technique: questionnaire was filled by the participants.

Sample Size \& Sampling Technique: It was decided to collect information from all junior doctors of this institution, but is spite of repeated visit only 244 were available during thedata collection period. All gave consent for participation in the study. Thus the response rate was cent percent. Non random purposive sampling technique was followed.

Study Variables: a. Sociodemographic Variables (five items): (1) age (in completed years); (2) gender (male/female/others); (3) place of residence (hostel resident/day scholar); (4) designation (intern/extern/house-staff/PGT); (5)TB training received in the last one year (yes/no).

b. Knowledge about STCI Guideline (20 Questions): (1) Highest TB burden country globally; (2) full form of RNTCP; (3) full form of DOTS; (4) number of standards present in STCI; (5) criteria of presumptive adult pulmonary TB patient; (6) diagnostic technology for adult pulmonary TB; (7) number of sputum samples collected; (8) additional diagnostic test in children; (9) diagnostic test in paediatric TB \& PL-HIV; (10) heard about MDR-TB; (11) definition of MDR- TB; (12) diagnosis of MDR-TB; (13) definition of XDR TB; (14) drug regimen for newly diagnosed TB; (15) drug regimen for previously treated TB; (16) follow up sputum test for newly diagnosed TB; (17) follow up sputum test for previously treated TB; (18) is TB a notifiable disease in India; (19) treatment of HIV infected TB patient; (20) INH chemoprophylaxis.

c. Attitude toward STCI (4 views): (1) TB is a highly infectious but curable disease; (2) Disclose if inflicted with; (3) Consider that they or their family members are at high risk of getting TB; (4) Regular upgradation of TB knowledge.

d. Practice on STCI (4 questions): (1) Laboratory test advise for diagnosis of presumptive adult pulmonary TB; (2) Drug prescribe as per STCI; (3) Follow correct duration of treatment (4) Notify TB patients to RNTCP. e. Source(s) of information about STCI: (1) Books \& Journals (2) Seminar, workshop, CMEs; (3) Internet (4) Mass media; (4) Colleagues, friends; (5) Others
Methods of Data Collection: After obtaining the Institutional Ethics Committee(IEC) clearance, designing of questionnaire, it's pretesting \& minor modification was done, then nature and purpose of the study was explained to the study population, their anonymity and confidentiality were assured, then their informed written consent was obtained, and the questionnaire was self- administered.

Data Analysis: Software used for data analysis was: IBM Corp. Released 2013. IBM SPSS Statistics for Windows, Version 22.0. Armonk, NY: IBM Corp.

For descriptive statistics: Socio demographic variables; knowledge; attitude; practice; sources of information: Frequency (n) and proportion (\%) (95\% confidence interval).

For analytical statistics: Chi-square to test association; and multivariable logistic regression. Results were expressed in terms of odd's ratios (ORs); adjusted odd's ratio (AOR) with 95\% Confidence Intervals (CI). A p value of $<0.05$ considered as significant.

\section{Operational Definitions:}

1. Junior doctors: Interns, Externs, House- staffs, Post-graduate diploma and degree trainees (PGTs).

2. Residence: a) Hostel resident: Junior doctors residing at hostel; b) Day scholar: Junior doctors residing at home.

3. Training of TB: Attended any lecture, Workshop, Seminar, CME (Continuing Medical Education) during last 1 year regarding TB/RNTCP/STCI.

\section{Correct Knowledge:}

1. Highest TB burden country globally: India

2. Full form of RNTCP: Revised National Tuberculosis Control Programme

3. Full form of DOTS: Directly Observed Treatment Short Course

4. Number of Standards present in STCI guidelines: 26 Standards

5. Presumptive adult Pulmonary TB patient: A person with any of the symptoms and signs suggestive of TB including: Cough>2 weeks, Fever> 2 weeks, significant weight loss, hemoptysis etc., and any abnormality in chest Radiograph.

6. Diagnostic technology of presumptive Pulmonary TB: a) Microbiological confirmation: Sputum smear microscopy for AFB with at least two samples, including one early morning Sample; b) Chest X-ray (where available).

7. Number of sputum samples: Two

8. Additional diagnostic test in children: Tuberculin Skin Test (TST)-Mantoux test

9. Diagnosis of Paediatric TB \& TB HIV: Microbiological confirmation through sputum/gastric lavage; by CBNAAT/ microscopy/culture; TST.

10. Definition of MDR-TB: Multi Drug Resistant-TB: TB bacilli resistant to at least Isoniazid $(\mathrm{H})$ and 
Rifampicin (R), with or without resistance to other $1^{\text {st }}$ line anti TB drugs.

11. Definition of XDR TB: is a subset of MDR-TB where the bacilli, in addition to being resistant to $R$ and $\mathrm{H}$, are also resistant to fluoroquinolones and any one of the second-line injectable drugs (namely Kanamycin, Capreomycin or Amikacin).
12. Diagnosis of presumptive multi-drug resistant TB (MDR-TB): rapid molecular Drug Susceptibility Testing (DST) (as the first choice) or liquid / solid culture-DST/LPA/CB-NAAT.

13. Diagnostic test of MDR TB: rapid molecular DST (as the first choice) or liquid / solid culture-DST.

14. Drug regimen of TB:

\begin{tabular}{|l|c|c|c|}
\hline \multicolumn{1}{|c|}{ Type of TB cases } & Intensive Phase & Continuation Phase & Total duration \\
\hline New cases & 2(HRZE) & 4(HRE) & 6 months \\
\hline $\begin{array}{l}\text { Previously treated } \\
\text { cases }\end{array}$ & 2(HRZES)+ 1(HRZE) & 5(HRE) & 8 months \\
\hline
\end{tabular}

15. Is TB a notifiable disease in India: Yes; $A$ Government order issued by the GoI in May 2012 mandates all health care providers to notify every TB case diagnosed and /or treated to local health authorities

16. Follow up sputum examinations: One specimen at the time of completion of the intensive phase of treatment and one at the end of treatment.

17. Newly diagnosed TB patient: A TB patient who never received treatment for $\mathrm{TB}$ or received antiTB treatment for $<1$ month

18. Previously Treated TB patients: A TB patient who received ATT for 1 month or more in the past (Recurrent TB, Treatment after failure, Treatment after lost to follow-up).

\section{Favourable Attitude:}

1. Infectivity of $\mathrm{TB}: \mathrm{TB}$ is a highly infectious but curable disease.

2. Disclosure of TB status: Should be disclosed to any Healthcare professional(s)/Family member(s)

3. Seriousness of TB problem In India: Consider that they or their family members are at high risk of getting TB.

4. Want to upgrade TB knowledge.

Good Practices:

1. Specific investigations advised in a presumptive adult pulmonary TB patient: a) Sputum test for AFB; b) Chest X-Ray; c) CB-NAAT

2. Notify TB cases: to RNTCP

3. Prescribe correct drug regimen

4. Duration of TB treatment: 6 months fot CAT1 and 8 months for CAT 2.

\section{Sources of Knowledge}

1. Internet: Email, social media sites, websites

2. Mass Media: Film, Radio, Recorded music, Television

3. Books and Journals

4. Friends and colleagues

5. Seminar/workshops/CMEs

6. Others (faculty members, Pharmaceutical companies)

Calculation of Knowledge and Practice Score: For every correct answers a score of " 1 " was awarded $\&$ for every wrong /don't know answer " 0 " were awarded. Correct and incorrect answers were decided according to the operational definitions given. Mean score of the study population for both knowledge and practice were calculated. Satisfactory knowledge was defined as knowledge score more than mean score (excluding the mean itself) \& unsatisfactory knowledge was defined as knowledge score less than mean score (including the mean itself). Similarly good practice was defined as practice score more than mean score (excluding the mean itself) \& Bad practice was defined as practice score less than mean score (including the mean itself).

\section{Results}

A total of 244 junior doctors participated in the present study whose age ranged between 22 and 33 years; mean age and standard deviation were 25 and 0.79 years, respectively; About $62.70 \%$ of the study population were in the age group of 22-25 years; $66.80 \%$ were males; about $55.33 \%, 17.21 \%$ \& $27.46 \%$ were interns, house-staffs \& PGTs/PDTs respectively; $58.20 \%$ were hostel residents; and $77.46 \%$ of the junior doctors did not receive any TB training within last 1 year [Table 1].

Table 2 demonstrated the Knowledge \& practice scores regarding STCI guidelines among the participants. It was seen that Knowledge of more than half of the study population $(50.82 \%)$ was unsatisfactory. And practice score of only $25.25 \%$ was above the mean and hence considered as good practice.

Knowledge: Most $(>90 \%)$ of the junior doctors knew correctly the full form of RNTCP; however only $19 \%$ of them knew the correct number of guidelines in STCI; majority $(74.59 \%)$ identified one or more symptoms of presumptive TB correctly; more than $90 \%$ of the junior doctors answered sputum AFB test as the choice of diagnostic technology, followed by $70.7 \%$ answering chest X-Ray; approximately $34^{\text {th }}(76 \%)$ of the junior doctors gave the correct answer regarding additional test for diagnosis of Pediatric TB(Mantoux test); 72\% of junior doctors knew the test of choice for TB in child and PL-HIV; $91.39 \%$ of the junior doctors heard of MDR-TB \& almost $70 \%$ of those who heard the term MDR-TB knew the correct definition; however only $38 \%$ of those who heard MDR-TB knew the correct test 
for diagnosing MDR-TB; only $14 \%$ of the study population knew the current drug regimen as per STCI guidelines for newly diagnosed TB; \& less than a quarter $(23.36 \%)$ of them were updated about the current drug regimen for previously treated TB; about $31 \%$ of the participants had correct knowledge regarding follow up sputum test for newly diagnosed TB patients whereas $18.85 \%$ gave correct answer regarding the frequency of follow up sputum test for previously treated TB patients ; $78 \%$ of the junior doctors knew that TB is a notifiable disease in India; and $40.3 \%$ of the study population knew treatment of TB HIV co infection [Table 3].

Attitude \& Practice: Table 4 revealed attitude \& practices toward STCI guidelines among the study population. About $84 \%$ were aware that TB is a highly infectious but curable disease; $92.21 \%$ would want to disclose if he/she inflicted with TB; $74.59 \%$ considered that they or their family members are at high risk of getting TB and $91.80 \%$ wanted to regular upgrade their TB knowledge. Regarding practice, $(90.16 \%)$ of the study population preferred sputum test followed by $70 \%$ for chest x-ray for diagnosis of TB. About $71 \%$ doctors followed correct duration of treatment for new cases and $59 \%$ for previously treated ones; however 90\% prescribed an incorrect drug regimen for both new and previously treated cases. Only $1.64 \%$ of them notify TB patients to RNTCP.

Sources of Knowledge: Journals and books (69.26\%) followed by seminars $(48.77 \%)$ and Internet $(40 \%)$ were their main source of knowledge about STCI guidelines [Table 5].
Table 1: Distribution of the study population as per socio demographic profile $(\mathrm{N}=\mathbf{2 4 4})$

\begin{tabular}{|c|c|c|}
\hline $\begin{array}{c}\text { Socio } \\
\text { demographic } \\
\text { profile }\end{array}$ & Number (n) & $\begin{array}{c}\text { Percentage } \\
(\%)\end{array}$ \\
\hline \multicolumn{3}{|c|}{ Age (in years) } \\
\hline $22-25$ & 153 & 62.70 \\
\hline $26-29$ & 68 & 27.87 \\
\hline $30-33$ & 23 & 09.43 \\
\hline \multicolumn{3}{|c|}{ Gender } \\
\hline Male & 163 & 66.80 \\
\hline Female & 81 & 33.20 \\
\hline \multicolumn{3}{|c|}{ Designation } \\
\hline Intern & 135 & 55.33 \\
\hline House staff & 42 & 17.21 \\
\hline $\begin{array}{l}\text { Post graduate } \\
\text { trainees (PGT) }\end{array}$ & 67 & 27.46 \\
\hline \multicolumn{3}{|c|}{ Current residence } \\
\hline Hostel resident & 142 & 58.20 \\
\hline Day scholar & 102 & 41.80 \\
\hline \multicolumn{3}{|c|}{ TB training taken during last one year } \\
\hline Yes & 55 & 22.54 \\
\hline No & 189 & 77.46 \\
\hline Total & 244 & 100.00 \\
\hline
\end{tabular}

Table 2: Knowledge, attitude and practice score about STCI guidelines of RNTCP $(\mathbf{N}=\mathbf{2 4 4})$

\begin{tabular}{|l|c|c|}
\hline Score & Number (n) & Percentage (\%) \\
\hline Knowledge & & \\
\hline Satisfactory & 120 & 49.18 \\
\hline Unsatisfactory & 124 & 50.82 \\
\hline Attitude & & \\
\hline Positive & 190 & 77.87 \\
\hline Negative & 54 & 22.13 \\
\hline Practice & & \\
\hline Good & 86 & 35.25 \\
\hline Bad & 158 & 64.75 \\
\hline Total & $\mathbf{2 4 4}$ & $\mathbf{1 0 0 . 0 0}$ \\
\hline
\end{tabular}

Table 3: Distribution of the study population according to knowledge about STCI guidelines $(\mathrm{N}=244)$

\begin{tabular}{|l|c|c|}
\hline Knowledge & $\begin{array}{c}\text { Correct response } \\
\text { Number }(\mathbf{n})\end{array}$ & $\begin{array}{c}\text { Percentage } \\
(\mathbf{\%})\end{array}$ \\
\hline Highest TB burden country in world & 228 & 93.44 \\
\hline Full form of RNTCP & 231 & 94.67 \\
\hline Full form of DOTS & 231 & 94.67 \\
\hline Number of STCI guidelines & 46 & 18.85 \\
\hline Case definition of presumptive adult pulmonary TB & 182 & 74.59 \\
\hline Diagnostic technologies of adult pulmonary TB & 221 & 90.57 \\
\hline Number of sputum samples collected & 200 & 81.97 \\
\hline Additional test for diagnosis of Pediatric TB & 185 & 75.82 \\
\hline Diagnostic test of choice for TB in Child \& PL-HIV & 176 & 72.13 \\
\hline Heard about MDR TB & 223 & 91.39 \\
\hline Definition of MDR TB & 168 & 68.85 \\
\hline Diagnostic test of choice for MDR-TB & 110 & 45.08 \\
\hline Definition of XDR TB & 93 & 38.11 \\
\hline Drug regimen for newly diagnosed TB & 34 & 13.93 \\
\hline Drug regimen for previously treated TB & 57 & 23.36 \\
\hline
\end{tabular}




\begin{tabular}{|l|c|c|}
\hline Follow up sputum test for newly diagnosed TB & 75 & 30.74 \\
\hline Follow up sputum test for previously treated TB & 46 & 18.85 \\
\hline Heard about TB notification in India & 190 & 77.86 \\
\hline Treatment of TB HIV co infection & 98 & 40.16 \\
\hline INH chemoprophylaxis & 130 & 53.28 \\
\hline
\end{tabular}

Table 4: Distribution of the study population according to attitude and practice regarding $\mathrm{RNTCP}(\mathrm{N}=244)$

\begin{tabular}{|l|c|c|}
\hline Positive Attitude & Number (n) & Percentage (\%) \\
\hline TB is a highly infectious but curable disease & 205 & 84.01 \\
\hline Disclose if inflicted with TB & 125 & 51.23 \\
\hline $\begin{array}{l}\text { Consider that they or their family members are at high risk } \\
\text { of getting TB }\end{array}$ & 122 & 50.00 \\
\hline Regular upgradation of TB knowledge & 224 & 91.80 \\
\hline Good Practice & & \\
\hline $\begin{array}{l}\text { Specific laboratory test advise for diagnosis of presumptive } \\
\text { adult pulmonary TB }\end{array}$ & 220 & 90.16 \\
\hline Drug prescribe as per STCI for CAT 1 \& CAT 2 & 26 & 10.65 \\
\hline Follow correct duration of treatment for CAT 1 & 174 & 71.31 \\
\hline Follow correct duration of treatment for CAT 2 & 145 & 59.43 \\
\hline Notify TB cases to RNTCP & 04 & 01.64 \\
\hline
\end{tabular}

Table 5: Sources of STCI guideline knowledge $(\mathrm{N}=244) *$ Multiple response

\begin{tabular}{|l|c|c|}
\hline Source of knowledge & Number (n) & Percentage (\%) \\
\hline Books \& Journals & 169 & 69.26 \\
\hline Seminar, workshop, CMEs & 119 & 48.77 \\
\hline Internet & 98 & 40.16 \\
\hline Mass media & 54 & 22.13 \\
\hline Colleagues, friends & 67 & 27.46 \\
\hline Others & 16 & 06.56 \\
\hline
\end{tabular}

\section{Discussion}

The present cross-sectional observational study was conducted among 244 randomly selected junior doctors of a tertiary care teaching hospital of Kolkata to assess their knowledge, attitude and practice regarding STCI guidelines of TB, so that gaps could be identified for subsequent remedial actions.

Knowledge: In this study, majority (93.44\%) of the study population knew correctly which is the highest TB burden country in the world in terms of absolute number of incident cases that occur each year (India), which was in line with a study by Raghavendra et al at Karnataka $(92.77 \%)^{6}$ and Chennaveerappa et al at Hassan Institute of Medical Sciences (82.99\%). ${ }^{7}$

Almost $95 \%$ of our study population could define the acronym of DOTS and RNTCP; this finding was in accordance with Rohtak study by Gupta et al, ${ }^{8}$ and Imphal study by Sangma et al (More than $95 \%) .{ }^{9}$

About $74.59 \%$ of the respondents correctly identified the case definition of presumptive TB (cough for more than two weeks); which was corroborative with the findings of Imphal $(75 \%),{ }^{9}$ Karnataka $(79.51 \%){ }^{6}$ Hassan Institute $(85.1 \%)^{7}$ and Pune by Bogam $(36.27 \%) .{ }^{10}$

With regard to TB diagnosis under STCI guidelines, $90.57 \%$ of the study population answered sputum microscopy as the investigation of choice; almost similar to study by Gupta et al $(97.3 \%$ \& $71.9 \%$ by interns \& PG students respectively $)^{8}$ and Sangma et al $(90.2 \%)$ wherein the majority of the study population relied primarily on sputum for diagnosis. ${ }^{9}$

Majority (78.9\%) correctly answered two as the total number of sputum samples to be collected in Imphal study ${ }^{9}$ and $83.2 \%$ in Hassan Institute of Karnataka $^{7}$ whereas in our study it was almost $80 \%$. However only $14.70 \%$ knew correctly the number of sputum samples in Pune ${ }^{10}$ as majority of participants stated 'three' sputum samples which was the old guidelines of RNTCP.

More than $60 \%$ answered correctly regarding categories, phases, duration of treatment and first line ATT drugs as per STCI guidelines in Imphal ${ }^{9}$ whereas it was $14 \%$ and $23.3 \%$ respectively for CAT I \& CAT II in the present study.

For the question regarding the number of categories as per STCI, $64.2 \%$ could correctly answer two categories; $93.2 \%$ could correctly answer the number of phases in which DOTS is given in RNTCP and $87.2 \%$ correctly answered the question of duration of treatment of cat-I as 6 months and cat-II as 8 months in Imphal ${ }^{9}$ the respective figures in our study were $73 \%, 79 \%$, and $88 \%$ respectively. 
About $68.85 \%$ of our study population knew correctly the definition of MDR TB ; and few of them knew correct definition of XDR TB(38.11\%); which was like Imphal $(55.6 \%),{ }^{9}$ Karnataka $(32.53 \%$ \& $49.39 \%$ respectively) ${ }^{6}$ Hassan Institute $(77.6 \%)^{7}$ and Pune (83.33\% \& $26.47 \%$ respectively). ${ }^{10}$

Knowledge regarding INH chemoprophylaxis for a child less than 6 years with a mother of active pulmonary tuberculosis was $53 \%$ in the present study; which was lower than Imphal $(68.2 \%)^{9}$ but higher than Karnataka $(3.61 \%)^{6}$ and slightly higher than Hassan Institute $(46.6 \%)^{7}$

Majority (>90\%) of the respondents correctly responded on the time interval for collection of sputum sample; however in Karnataka it was only $46.98 \%{ }^{6}{ }^{6}$

Serological tests for TB being banned in India was correctly answered by only $30 \%$ of the respondents in the present study and Imphal study. ${ }^{9}$

Attitude: Majority of the study population were aware that TB is a highly infectious but curable disease. ${ }^{11}$ Despite this fact, a large number would not disclose if they were inflicted with the disease for fear of being left out. This finding was in line with a study by Bhandari et al at Nasik. ${ }^{12}$

Although India is the highest TB burden country in the world, only very small proportion of junior doctors considered that they or their family members were at high risk of getting TB. This showed that they either believed that TB is not a common disease there or TB attacks only certain group of people. ${ }^{11,12}$

All practitioners had positive attitude towards regular upgradation of knowledge; Srivastava et al at Gwalior also revealed the similar finding. ${ }^{13}$

A reluctance to interact with TB patients for fear of personal safety was seen in $21 \%$ of the study population. $^{12}$

\section{Conclusion and Recommendations}

Though junior doctors had satisfactory knowledge about symptoms of presumptive TB; \& investigations for diagnosis; they had unsatisfactory knowledge regarding drug regimen, follow up sputum, diagnosis of MDR TB, XDR-TB and TB HIV. Our study population had favorable attitude regarding seriousness of TB and regular upgradation of TB knowledge. They had discordant practices about drug regimen, duration of treatment, and TB notification.

Structured and periodic training and re-training to ensure continuity of correct knowledge is need of the hour. Misconceptions and unfavorable attitudes should be addressed. Correct treatment regimen \& follow-up should be emphasized.

\section{Acknowledgements}

We are thankful to Prof. (Dr.) R. N. Misra, Prof \& HOD, Department of Community Medicine, IPGME\&R, all the junior doctors who participated in the study, and undergraduate medical students of IPGME\&R, Kolkata.

\section{References}

1. WHO. Global Tuberculosis Report 2017. Executive Summary. World Health Organization 2017:p2. Available from

http://www.who.int/tb/publications/global_report/Exec_S ummary_13Nov2017.pdf?ua=1 [Accessed on 0403.2018].

2. TB in India - Elimination, Private Care, TB burden, NSPs. Available from https://www.tbfacts.org/tb-india/_[Accessed on 14.03.2018].

3. TB burden estimates, notifications and treatment outcomes for individual countries and territories, who regions and the world. Available from http://www.who.int/tb/publications/global_report/gtbr201 7_annex4.pdf?ua=1_[Accessed on 14.03.2018].

4. WHO. Standards for TB care in India. World Health Organization Country office for India 2014..Available from

http://www.searo.who.int/india/mediacentre/events/2014/ stci_book.pdf?ua=1 [Accessed on 15.03.2018].

5. Revised National Tuberculosis Control Programme. National strategic plan for tuberculosis elimination 20172025.March 2017. Central TB Division, Directorate General of Health Services, Ministry of Health with Family Welfare, Nirman Bhavan, New Delhi 2017.

6. Raghavendra L, Babu SP, Shivakumar KM. Assessment of knowledge of intern doctors of a medical college hospital in Karnataka on revised national TB control programme. Int J Adv Med 2017;4:1123-7.

7. Chennaveerappa P. K, Rajashekar H. K, Jayashree Nagaral, Halesha B. R, Raghavendra Prasad K. U, Vinaykumar M. V, Nareshkumar M. N. "A Study on Awareness of Tuberculosis and RNTCP among Undergraduate Medical students and Interns". Journal of Evolution of Medical and Dental Sciences 2014;3(29):8115-8121.

8. Gupta KB, Mehta D, Sachdeva R, Sachdeva S. Knowledge of doctors, interns and final year medical students on selected parameters of tuberculosis and RNTCP. Journal, Indian Academy of Clinical Medicine 2016;17(3):198-200.

9. Sangma BK, Shivalingaiah B, Singh WA, Renthlei L, Sangma R. Assessment of Knowledge on management of Pulmonary Tuberculosis under RNTCP among graduating Interns and Postgraduate students in RIMS Imphal. IOSR Journal of Nursing and Health Science 2017;6(3):07-11.

10. Bogam RR. Awareness of medical interns regarding recent guidelines of revised national tuberculosis control programme of India. Int J Health Sci Res. 2014;4(1):160164.

11. Acharya PR, D'Souza M, Sahoo RC. Tuberculosis knowledge and attitude in aspiring doctors and nurses - Is it time for our TB teaching methods to evolve? Indian Journal of Tuberculosis 2017, 64(1):20-25.

12. Bhandari SR, Bande R. Knowledge, Attitude and Practice against Tuberculosis Infection Control among Medical Students and Nursing Staff. J Cont Med A Dent 2016;4(2):29-32.

13. Srivastava DK, Mishra R, Mishra S, Bansal M. A comparative assessment of KAP regarding tuberculosis and RNTCP among government and private practitioners in District Gwalior, India: An operational research. The Indian journal of tuberculosis 2011;58(4):168-77. 